\title{
Vitamin E Affects Lung Biochemical and Morphologic Response to Hyperoxia in the Newborn Rabbit
}

\author{
DAVID F. WENDER, GUNILLA E. THULIN, G. J. WALKER SMITH, AND JOSEPH B. WARSHAW ${ }^{(41}$ \\ Division of Perinatal Medicine. Departments of Pediatrics and Obstetrics and Gy'necology, and Department of \\ Pathologi. Yale University School of Medicine. New Haven, Connecticut, USA
}

\section{Summary}

The effects of parenteral vitamin $E$ treatment on aspects of the pulmonary biochemical and morphologic response to $100 \%$ oxygen were studied in newborn rabbits manifesting chemical evidence of vitamin $\mathrm{E}$ deficiency. Pups treated with $2 \mathrm{mg} / 100 \mathrm{~g}$ body weight increased serum vitamin E levels from 0.39 to $2.17 \mathrm{mg} / \mathrm{dl}$ by $72 \mathrm{hr}$ and lung tissue vitamin $E$ content from 3.52 to $17 \mathrm{mg} / \mathrm{mg}$ wet weight of lung. In vitro lipid peroxidation in lung homoginates of animals in 100\% oxygen for $72 \mathrm{hr}$ was inhibited by approximately $80 \%$ in animals receiving $100 \%$ oxygen plus vitamin E. Hyperoxiainduced increases in the pulmonary antioxidant enzymes, superoxide dismutase, glutathione peroxidase, and glutathione reductase were diminished by vitamin $E$ administration. Lungs from vitamin E-treated animals did not show the early lung epithelial injury seen in animals exposed to $100 \%$ oxygen but not treated with vitamin $E$. Mophometric analysis of lungs of animals in room air for $72 \mathrm{hr}$ showed $81.6 \%$ of lung to be normal as compared with 43.3\% normal lung in the group maintained in $100 \%$ oxygen for 72 hr. In the group treated with oxygen plus vitamin $E$, the lungs were similar to room air controls $(82.6 \%$ normal). This study thus provides further evidence for a direct antioxident affect of vitamin F in lung.

\section{Speculation}

These findings provide further evidence of antioxidant protection of lung by vitamin $E$ and suggest that the antioxidant effect of vitamin $E$ may involve an inactivation of the probable stimulus for antioxidant enzyme induction, oxygen-free radicals.

Although oxygen is essential for survival of aerobic organisms, in excess, it can produce toxic effects which result in tissue injury. The lung is particularly vulnerable to the toxic effects of oxygen because the pulmonary epithelium may be exposed directly to high concentrations of oxygen. In the human neonate, bronchopulmonary dysplasia (BPD) has been linked to prolonged oxygen therapy for neonatal hyaline membrane disease (HMD), and although the etiology of BPD is most likely multifactorial, direct lung parenchymal injury by oxygen is postulated to be a major etiologic factor $(6,24,26)$. Concern for the frequency with which BPD complicates recovery from HMD has prompted extensive research into methods of preventing or counteracting the toxic effects of oxygen on neonatal lung (38).

A preliminary clinical study from our group showed that administration of the antioxidant $d l-\alpha$-tocopherol (vitamin E) ameliorated the course of BPD in infants recovering from HMD, suggesting that neonatal lung antioxidant protection could be augmented by vitamin $E$ treatment (7). To further test this hypothesis, we have examined the influence of vitamin $E$ treatment on the biochemical and morphologic response to hyperoxia in the newborn rabbit.

\section{MATERIALS AND METHODS}

New Zealand White rabbit pups were delivered by caesarean section one day before term and were randomized by weight and litter into three equal groups. All groups were maintained in incubators at $32^{\circ} \mathrm{C}$ and were fed a modification of the diet described by Aprille and Rulfs (1) consisting of $15 \mathrm{~g}$ egg albumin. $2 \mathrm{~g}$ lactose. and $8 \mathrm{~g}$ corn oil diluted with water to a total volume of $100 \mathrm{ml}$. The pups were fed this synthetic formula once a day via sialastic tubing inserted into the stomach, each pup receiving volumes of $8 \%$ of body weight on day one, $10 \%$ on day two, and $12 \%$ on day three. Group I was maintained in room air, whereas groups II and III were maintained in $100 \%$ oxygen as periodically confirmed by Beckman oxygen analyzer. Animals in group III received vitamin $E$ (free alcohol; Hoffmann-LaRoche, Nutley, N.J.), $2 \mathrm{mg} / 100 \mathrm{~g} /$ day intramuscularly. In studies of lung histology, vitamin $\mathrm{E}$ dose was increased to $6 \mathrm{mg} / 100 \mathrm{~g} /$ day.

Pups were sacrificed by decapitation at birth and at 24-hr intervals up to $72 \mathrm{hr}$. Blood from two pups was collected in heparinized tubes, and the plasma was retained and frozen for vitamin E determinations. Before removal of the lungs, the thoracic cavity was exposed ventrally, and the left ventricle was incised. The pulmonary artery was cannulated and perfused with $10 \mathrm{cc}$ of $0.9 \%$ saline solution to remove blood from the pulmonary vascular bed. Lung tissue from two pups was pooled and homogenized in 0.05 potassium phosphate buffer $(\mathrm{pH} 7.8)$ at a $1: 10 \mathrm{w} / \mathrm{v}$ dilution using a Brinkman Polytron tissue homogenizer. A cytosol fraction was prepared by centrifuging the crude homogenate at $700 \times g$ for $10 \mathrm{~min}$ to remove nuclei and debris, at $8000 \times g$ for 10 min to remove mitochondria, and then at $100,000 \times g$ for 60 min. Aliquots of the crude homogenate and cytosol fractions were frozen for later assays.

Plasma vitamin E was determined using a modification of the technique of Fabianek et al. (8). Lung tissue vitamin E content was determined using the method of Taylor et al. (34). Stability of red blood cells to hydrogen peroxide $\left(\mathrm{H}_{2} \mathrm{O}_{2}\right)$ hemolysis was assessed according to the method of Horwitt et al. (17). Superoxide dismutase (EC 1.15.1.1) activity was determined on lung homogenates by measuring the inhibition of the autoxidation of epinephrine (22). Glutathione peroxidase (EC 1.11.1.9) activity in the lung cytosol fractions was determined as described by Paglia and Valentine (25). Glutathione reductase (EC 1.6.4.2) activity in homogenates was determined by the method of Horn (15). In vitro lipid peroxide formation by lung tissue was assessed using a modification of the 2-thiobarbituric acid method to quantify the production of malonyldialdehyde (29). Protein concentrations were determined on lung homogenates and cytosol fractions by the method of Lowry et al. (20). After routine fixation, embedding, and sectioning, lung sections were stained with hematoxylin and eosin for histologic examination. Specimens were compared qualitatively by an unbiased observer who then quantitated the extent of tissue abnormality for each specimen using the morphometric point-counting technique of Weibel (35). 
Before statistical analysis, arcsin transformations $\left(\mathrm{x}^{\prime}=2\right.$ $\arcsin \sqrt{x}$ ) were performed on the $\mathrm{H}_{2} \mathrm{O}_{2}$ hemolysis data and morphometry data to normalize the binomial nature of these proportional measures (37). Because each experiment had been conducted on littermates, repeated-measures analysis of variance (ANOVA) was then applied in the statistical analysis of these transformed proportions and all nonporportional data. Preliminary omnibus analyses revealed significant treatment effects for every variable. Based on these initial analyses, separate repeatedmeasures ANOVAs were conducted on 24-, 48-, and 72-hr data for each variable. Newman-Keuls post-hoc analyses (37) were then performed on those repeated measures ANOVAs which were significant.

\section{RESULTS}

\section{BIOCHEMISTRY}

The mean plasma vitamin E level was $0.39 \mathrm{mg} / \mathrm{dl}$ at birth. As shown in Table 1, the mean plasma concentration of vitamin $E$ in the room air and 100\% oxygen groups increased only about 2-fold by $72 \mathrm{hr}$ and did not differ from each other significantly. At a daily vitamin $\mathrm{E}$ dose of $2 \mathrm{mg} / 100 \mathrm{~g}$, the mean plasma vitamin $\mathrm{E}$ level increased over $72 \mathrm{hr}$ to $2.17 \mathrm{mg} / \mathrm{dl}$ and was significantly higher than the $72-\mathrm{hr}$ results for the two other experimental groups. Animals treated with $6 \mathrm{mg} / 100 \mathrm{~g} /$ day had a mean plasma vitamin $\mathrm{E}$ level of $9.04 \mathrm{mg} / \mathrm{dl}$ at $72 \mathrm{hr}$. Tissue levels of vitamin $\mathrm{E}$ in lung during the study period are shown in Table 2. At $72 \mathrm{hr}$, mean vitamin $E$ content of lung of the group in 100\% oxygen treated with vitamin $\mathrm{E}(2 \mathrm{mg} / 100 \mathrm{~g} /$ day $)$ was $17 \mu \mathrm{g} / \mathrm{mg}$ wet weight as compared with approximately $4 \mu \mathrm{g} / \mathrm{mg}$ wet weight in both the room air and 100\% oxygen groups.

Results for the red blood cell $\mathrm{H} . \mathrm{O}: 2$ hemolysis test are presented in Table 3. For both the room air and $100 \% \mathrm{O}$. groups, percentage of red cell hemolysis increased during the course of the experiment. However, for the oxygen-exposed group treated with vitamin $E$,

Table 1. The influence of vitamin $E$ on the plasma vitamin E level Plasma vitamin E level $(\mathrm{mg} / \mathrm{dl})$

\begin{tabular}{llll} 
Age & Room air & $100 \%$ oxygen & $\begin{array}{c}100 \% \text { oxygen }+ \\
\text { vitamin E }\end{array}$ \\
\hline Birth & $0.39 \pm 0.05^{1}$ & & \\
$24 \mathrm{hr}$ & $0.29 \pm 0.08$ & $0.58 \pm 0.16$ & $2.06 \pm 0.48^{2}$ \\
$48 \mathrm{hr}$ & $0.46 \pm 0.10$ & $0.46 \pm 0.13$ & $3.01 \pm 0.51^{2}$ \\
$72 \mathrm{hr}$ & $0.61 \pm 0.08$ & $0.82 \pm 0.12$ & $2.17 \pm 0.40^{2}$ \\
\hline
\end{tabular}

${ }^{\prime}$ Mean \pm S.E. of six experiments. Vitamin E dose was $2 \mathrm{mg} / 100 \mathrm{~g} /$ day.

${ }^{2}$ Statistically significant difference from room air and $100 \%$ oxygen groups $(P<0.01)$. Values for the room air group were not significantly different from those of the $100 \%$ oxygen group. Statistical significance was determined by repeated measures analysis of variance with NewmanKeuls post-hoc test.

Table 2. The influence of vitamin $E$ on lung tissue vitamin $E$ content

Lung vitamin E content ( $\mu \mathrm{g} / \mathrm{mg}$ wet wt)

\begin{tabular}{lccc} 
& \multicolumn{2}{c}{ Lung vitamin E content $(\mu \mathrm{g} / \mathrm{mg}$ wet wt $)$} \\
\cline { 2 - 4 } Age & Room air & 100\% oxygen & $\begin{array}{c}\text { 100\% oxygen }+ \\
\text { vitamin } \mathrm{E}\end{array}$ \\
\hline Birth & $3.52 \pm 0.33^{1}$ & & \\
$24 \mathrm{hr}$ & $4.36 \pm 0.54$ & $4.12 \pm 0.26$ & $9.44 \pm 0.67^{2}$ \\
$48 \mathrm{hr}$ & $3.76 \pm 0.34$ & $3.52 \pm 0.22$ & $10.36 \pm 1.27^{2}$ \\
$72 \mathrm{hr}$ & $4.32 \pm 0.26$ & $3.96 \pm 0.25$ & $17.04 \pm 0.86^{2}$ \\
\hline
\end{tabular}

${ }^{1}$ Mean \pm S.E. of five experiments. Experimental conditions and statistical analysis otherwise were as described in Table 1.

${ }^{2}$ Statistically significant difference from both the room air and $100 \%$ oxygen groups $(P<0.01)$. Values for the room air group did not differ significantly from those of $100 \%$ oxygen group. a marked resistance to $\mathrm{H}_{2} \mathrm{O}_{2}$-induced hemolysis developed with cumulative vitamin $\mathrm{E}$ treatment.

In vitro lipid peroxide formation was assessed in lung homogenate from animals maintained in 100\% oxygen with or without vitamin E treatment. As shown in Table 4, $72 \mathrm{hr}$ of oxygen exposure resulted in increased lipid peroxide formation in animals not treated with vitamin $E$. However, in vitamin E-treated animals, lipid peroxide formation fell with cumulative vitamin $\mathrm{E}$ treatment so that by $72 \mathrm{hr}$, lipid peroxide formation had been inhibited by approximately $80 \%$.

Results for lung homogenate superoxide dismutase activity are presented in Table 5. During the course of the experiment, a gradual increase in superoxide activity was observed in animals exposed to $100 \%$ oxygen without vitamin $\mathrm{E}$ treatment. In contrast, animals treated with vitamin $E$ demonstrated much smaller increases in superoxide dismutase activity in response to oxygen. Results for that group did not differ significantly from room air

Table 3. The influence of vitamin $E$ on ervthrocvte sensitivity to $\mathrm{H}_{2} \mathrm{O}_{2}$ hemolysis

\begin{tabular}{lllc}
\hline & \multicolumn{3}{c}{ \% erythrocytes hemolyzed } \\
\cline { 2 - 4 } Age & Room air & 100\% oxygen & $\begin{array}{c}10 \% \%_{\text {oxygen }+} \\
\text { vitamin E }\end{array}$ \\
\hline Birth & $30.8 \pm 10.9^{1}$ & & \\
$24 \mathrm{hr}$ & $55.5 \pm 12.4$ & $62.1 \pm 10.6$ & $15.6 \pm 5.5^{2}$ \\
$48 \mathrm{hr}$ & $47.5 \pm 13.5$ & $73.4 \pm 7.5$ & $5.4 \pm 1.1^{2}$ \\
$72 \mathrm{hr}$ & $71.9 \pm 9.9$ & $80.1 \pm 8.5$ & $3.7 \pm 0.4^{2}$ \\
\hline
\end{tabular}

' Mean \pm S.E. Experimental conditions and statistical analysis were as described in Table 1 .

"Statistically significant difference from both the room air and $100 \%$ oxygen groups $(P<0.01)$. Values for the room air groups differed significantly from the $100 \%$ oxygen group at $48 \mathrm{hr}$ only $(P=0.05)$

Table 4. The influence of vitamin $E$ on the response to hyperoxia for in vitro lung lipid peroxidation

In vitro lipid peroxide formation

(nmoles malonyldialdehyde produced per mg protein)

\begin{tabular}{lcc}
\multicolumn{1}{c}{ Age } & 100\% oxygen & 100\% oxygen + vitamin E \\
Birth & $67.6 \pm 18.8^{1}$ & \\
$24 \mathrm{hr}$ & $77.9 \pm 14.6$ & $57.6 \pm 12.1$ \\
$48 \mathrm{hr}$ & $65.8 \pm 21.6$ & $48.8 \pm 26.0$ \\
$72 \mathrm{hr}$ & $96.0 \pm 18.0$ & $22.5 \pm 2.5^{2}$ \\
\hline
\end{tabular}

'Mean \pm S.E. Experimental conditions and statistical analysis were as described in Table 1 .

${ }^{2}$ Statistically significant difference from the $100 \%$ oxygen group $(P<$ 0.01 ).

Table 5. The influence of vitamin $E$ on the response to $100 \%$ oxygen of lung homogenate superoxide dismutase activity

\begin{tabular}{|c|c|c|c|}
\hline \multirow[b]{2}{*}{ Age } & \multicolumn{3}{|c|}{ Superoxide dismutase $\left(\mathrm{ng} / \mathrm{mg}\right.$ protein $\times 10^{2}$ ) } \\
\hline & Room air & $100 \%$ oxygen & $\begin{array}{c}100 \% \text { oxygen }+ \\
\text { vitamin } \mathrm{E}\end{array}$ \\
\hline Birth & $6.40 \pm 0.52^{1}$ & & \\
\hline $24 \mathrm{hr}$ & $6.33 \pm 0.61$ & $6.67 \pm 0.63$ & $6.35 \pm 0.55$ \\
\hline $48 \mathrm{hr}$ & $6.58 \pm 0.60$ & $8.55 \pm 0.64^{2}$ & $6.79 \pm 0.42$ \\
\hline $72 \mathrm{hr}$ & $6.47 \pm 0.47$ & $9.87 \pm 0.64^{2}$ & $7.29 \pm 0.56$ \\
\hline
\end{tabular}

' Mean \pm S.E. Experimental conditions and statistical analysis were as described in Table 1 .

"Statistically significant difference from both the room air and $100 \%$ oxygen + vitamin E groups $(P<0.01)$. Values from the room air groups did not differ significantly from those of the $100 \%$ oxygen plus vitamin $E$ group at any time. 
Table 6. The influence of vitamin $E$ on the response to $100 \%$ oxygen of lung cytosol glutathione peroxidase activity

Glutathione peroxidase

(nmoles $\mathrm{NADPH} / \mathrm{min} / \mathrm{mg}$ protein $\times 10^{2}$ )

\begin{tabular}{lccc}
\cline { 2 - 4 } \multicolumn{1}{c}{ Age } & Room air & $100 \%$ oxygen & $\begin{array}{c}100 \% \text { oxygen }+ \\
\text { vitamin } E\end{array}$ \\
\hline Birth & $17.38 \pm 1.16^{1}$ & & \\
$24 \mathrm{hr}$ & $12.75 \pm 1.27$ & $22.71 \pm 6.20$ & $16.88 \pm 4.41$ \\
$48 \mathrm{hr}$ & $16.33 \pm 2.80$ & $20.18 \pm 2.11$ & $17.45 \pm 2.36$ \\
$72 \mathrm{hr}$ & $12.91 \pm 1.36$ & $18.16 \pm 1.89^{2}$ & $14.62 \pm 0.98$ \\
\hline
\end{tabular}

${ }^{1}$ Mean \pm S.E. of five experiments. Experimental conditions and statistical analysis otherwise were as described in Table 1.

${ }^{2}$ Statistically significant difference from both the room air and $100 \%$ oxygen + vitamin E groups $(P<0.05)$. Values for the room air group did not differ significantly from those of the $100 \%$ oxygen plus vitamin $E$ group at any time.

Table 7. The influence of vitamin $E$ on the response to $100 \%$ oxygen of lung homogenate glutathione reductase activity

Glutathione reductase

(nmoles NADPH $/ \mathrm{min} / \mathrm{mg}$ protein)

\begin{tabular}{lccc} 
& Room air & $100 \%$ oxygen & $\begin{array}{c}\text { 100\% oxygen }+ \\
\text { vitamin E }\end{array}$ \\
\hline Birth & $13.92 \pm 1.56^{1}$ & & \\
$24 \mathrm{hr}$ & $14.56 \pm 2.38$ & $16.10 \pm 0.76$ & $14.44 \pm 2.19$ \\
$48 \mathrm{hr}$ & $16.65 \pm 2.50$ & $18.68 \pm 2.99$ & $15.04 \pm 3.21$ \\
$72 \mathrm{hr}$ & $14.04 \pm 1.25$ & $18.76 \pm 2.54^{2}$ & $14.23 \pm 1.77$ \\
\hline
\end{tabular}

${ }^{1}$ Mean \pm S.E. Experimental conditions and statistical analysis were as described in Table 1 .

- $S$ tatistically significant difference from both the room air and $100 \%$ oxygen plus vitamin $\mathrm{E}$ groups $(P<0.05)$. Values for the room air group did not differ significantly from those of the $100 \%$ oxygen plus vitamin $E$ group at any time.

controls at any experimental time and were significantly less at 48 and $72 \mathrm{hr}$ than those of the animals exposed to $100 \%$ oxygen but not treated with vitamin $E$.

Findings for lung glutathione peroxidase and glutathione reductase were similar to those for superoxide dismutase and are presented in Tables 6 and 7, respectively. For these glutathione system enzymes, pulmonary activites were consistently highest in the $100 \%$ oxygen group at each experimental time. Although these increases did not reach statistical significance at 24 and $48 \mathrm{hr}$, results for both enzymes at $72 \mathrm{hr}$ were significantly elevated over corresponding results for the two other experimental groups. For animals treated with vitamin E during exposure to $100 \%$ oxygen, lung glutathione peroxidase and glutathione reductase activities did not differ from room air controls at any time.

Lung protein content did not vary significantly among the three experimental groups. Injection of the solubilizing vehicle for vitamin $\mathrm{E}$ was without effect on either enzyme activity or in vitro lipid peroxidation in animals exposed to oxygen.

\section{MORPHOLOC;Y}

The influence on lung morphology of exposure to $100 \%$ oxygen for $72 \mathrm{hr}$ is shown in Fig. 1. After $72 \mathrm{hr}$, lung specimens demonstrated light microscopic evidence of early epithelial injury. This injury was characterized by focal atelectasis peripherally and around bronchioles, with adjacent zones of overexpansion of alveoli and dilation of small airways (emphysema).

When lungs from rabbits receiving vitamin E, $2 \mathrm{mg} / 100 \mathrm{~g} / \mathrm{day}$. were examined after $72 \mathrm{hr}$ exposure to $100 \%$ oxygen, there was no consistent morphologic evidence of protection from oxidant in- jury. However, at a vitamin $\mathrm{E}$ dose of $6 \mathrm{mg} / 100 \mathrm{~g} / \mathrm{day}$, lung specimens were indistinguishable after $72 \mathrm{hr}$ oxygen exposure from animals maintained in room air. Figures 2 and 3 are representative photomicrographs from animals from the room air group and the vitamin $\mathrm{E}$ treated $100 \%$ oxygen group, respectively. As depicted in these photomicrographs, specimens were similar histologically, in that alveoli were of uniform size and shape, alveolar walls were delicate, and no atelectasis or emphysema were observed.

Results of a morphometric quantitation of the percentage of atelectasis and percentage of emphysema are presented in Table 8. Specimens from the $100 \%$ oxygen group averaged approximately four times the amount of atelectasis and two times the amount of emphysema seen in the room air and vitamin E-treated groups. In the group exposed to oxygen but treated with vitamin $E$, the extent of atelectasis and emphysema was not increased significantly compared to room air controls.

\section{DISCUSSION}

Prolonged exposure to high concentrations of oxygen will cause damage to pulmonary parenchyma. This oxidant injury appears to be mediated by the generation of free radicals, such as the superoxy radical $\left(\mathrm{O}_{2}\right)$, the perhydroxy radical ( $\left.\mathrm{HOO}\right)$, and the hydroxy radical $\left(\mathrm{OH}^{\circ}\right)$, formed in vivo during the univalent reduction of molecular oxygen $(3,9,11,12)$. These highly reactive free radicals result in tissue injury through peroxidation of membrane lipids or reaction with sulfhydryl groups to damage enzymes or structural proteins $(5,14,31)$.

The ability of organisms to withstand oxidant injury is determined in part by cellular antioxidant defenses. Among the endogenous pulmonary antioxidants are several enzymes which mediate the deactivation of free radicals. Superoxide dismutase catalyzes the reaction $\mathrm{O}_{2}^{-}+\mathrm{O}_{2}^{-}+2 \mathrm{H}^{+} \mathrm{H}_{2} \mathrm{O}_{2}+\mathrm{O}_{2}$ and appears to be a primary cellular defense against the superoxy radical (28). In the glutathione system, glutathione peroxidase inhibits lipid peroxidation by reducing peroxy fatty acids while simultaneously oxidizing glutathione. In a reaction linked to an NADPH-generating system, glutathione reductase then replenishes reduced glutathione (19). The activities of lung superoxide dismutase, glutathione peroxidase, and glutathione reductase have all been shown to increase with hyperoxic stress, and such increases are felt to represent an adaptive response to the greater potential for oxidant injury which accompanies exposure to high concentrations of oxygen $(4,10,23,39)$. The increased activities of superoxide dismutase, glutathione peroxidase, and glutathione reductase found in animals in our 100\% oxygen group provide further confirmation that pulmonary antioxidant enzyme activities increase in response to hyperoxia.

Among chemical antioxidants which may protect the lung from oxidant injury is vitamin $E$. Several investigators have demonstrated that vitamin E deficiency enhances the toxic effects of oxygen upon the lung $(18,27,32)$, and Taylor et al. (33) has shown that vitamin $E$ treatment of vitamin E-deficient rats significantly decreases lung damage in animals exposed to oxidant stress. Evidence that vitamin $\mathrm{E}$ ameliorates bronchopulmonary dysplasia in human infants has also been reported (7).

Although the precise mechanism by which vitamin $E$ functions as an antioxidant has yet to be determined, speculation on its mechanism of antioxidant protection has centered on at least two areas. Lucy (21) has speculated that vitamin E may be a structural component of membranes which makes membrane polyunsaturated fatty acid (PUFA) more resistant to peroxidation. Alternatively, others have provided evidence for a more direct antioxidant role for vitamin $\mathrm{E}$ as a tissue free radical scavenger (30).

In our non-vitamin E-treated animals, plasma vitamin $E$ levels rose slightly over 3 days of artificial feedings, reflecting the small amounts of vitamin $E$ which is normally present in corn oil $[7 \mathrm{mg}$ tocopherol per $100 \mathrm{~g}(13)$ ]. Despite this basal dietary vitamin E intake in our untreated animals, the rapid increase in erythrocyte sensitivity to $\mathrm{H}_{2} \mathrm{O}_{2}$ hemolysis observed in these animals suggests 


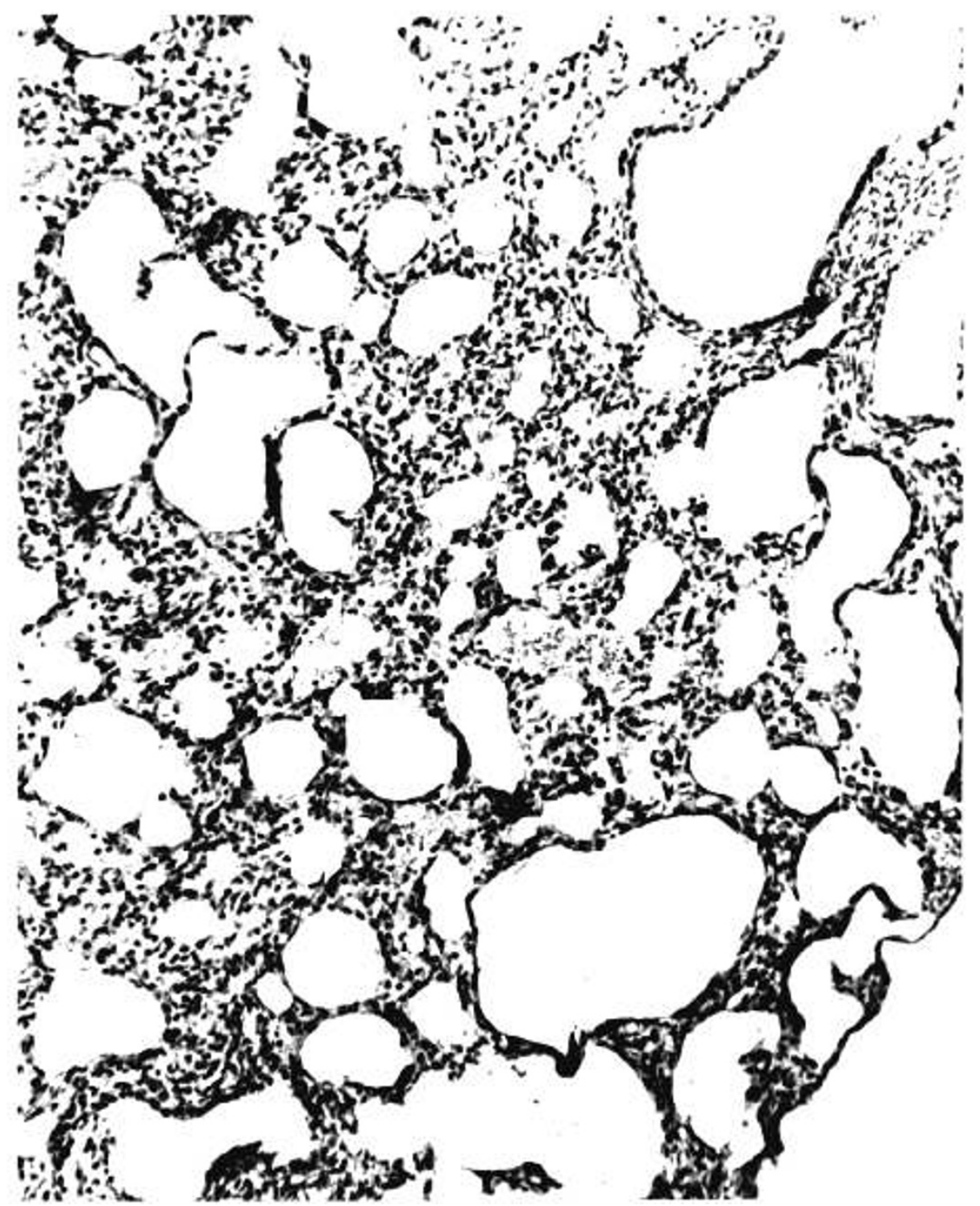

Fig. 1. A light micrograph of lung from a 72 -hr-old rabbit maintained in 100\% oxygen since birth. Early epithelial injury is apparent and is characterized by focal atelectasis with adjacent zones of alveolar emphysema and small airway dilation. (Hematoxylin and eosin: original magnification, $\times 140$.

that these artificially fed newborn rabbits quickly manifested chemical evidence of vitamin E deficiency. This deficiency most likely reflects the high PUFA intake from corn oil (56\%) linoleic acid (13) in our experimental animals, because high PUFA intake is known to augment requirements for vitamin $E(13,16,36)$. Because Frank et al. (10) have shown that nursed newborn rabbits are relatively resistant to pulmonary oxygen toxicity and demonstrate only minor morphologic changes after 7 days exposure to $100 \%$ oxygen, our morphologic findings of acute epithelial injury after $72 \mathrm{hr}$ of $100 \%$ oxygen exposure provide additional evidence that nutritional factors such as vitamin $\mathrm{E}$ may alter susceptibility to pulmonary oxygen toxicity $(18,27,32)$. The increased susceptibility to oxygen toxicity seen in the present study also may be due to deficiency of factors such as selenium and other antioxidents found in normal milk.

Within this nutritional context, vitamin $\mathrm{E}$ was capable of affecting the biochemical and morphologic response to hyperoxia. When our experimental animals were treated with vitamin $E$ (2 $\mathrm{mg} / 100 \mathrm{~g} /$ day) while being exposed to $100 \%$ oxygen, lung vitamin $\mathrm{E}$ content was increased, and the susceptibility of lung tissue to in vitro lipid peroxidation was dramatically reduced. These findings suggest that additional lung antioxidant protection was provided by vitamin $\mathrm{E}$ treatment.
Additionally, vitamin E treatment diminished the usual hyperoxia-induced increases in the pulmonary antioxidant enzymes superoxide dismutase, glutathione peroxidase, and glutathione reductase. These findings are consistent with the observations of Chow et al. (2) who, using ozone as an oxidant stress, have noted that ozone-induced increases in pulmonary antioxidant enzymes are diminished by vitamin $\mathrm{E}$ treatment. Both our findings and those of Chow et al. suggest that antioxidant protection of lung by vitamin $E$ may involve the inactivation of the likely stimuli for antioxidant enzyme induction, oxygen free radicals. Although a generalized inhibition of cell metabolic activity by vitamin $\mathrm{E}$ might be an alternative interpretation of these enzyme findings, we feel this is very unlikely because we have observed that another lung metabolic response to hyperoxia, the hyperoxia-induced increase in the oxidation of glucose to lactate, is unaffected by vitamin E treatment (R. E. Kimura, O. F. Wender, and J. B. Warshaw, unpublished observation).

Although at a dose of $2 \mathrm{mg} / 100 \mathrm{~g} /$ day, vitamin $\mathrm{E}$ altered the lung biochemical response to hyperoxia, a protective effect of vitamin $E$ treatment could not be demonstrated at that dose. The discrepancy suggested that at low doses, although vitamin $\mathrm{E}$ scavenges sufficient free radicals to blunt the lung biochemical response to hyperoxia, structural damage could continue because 


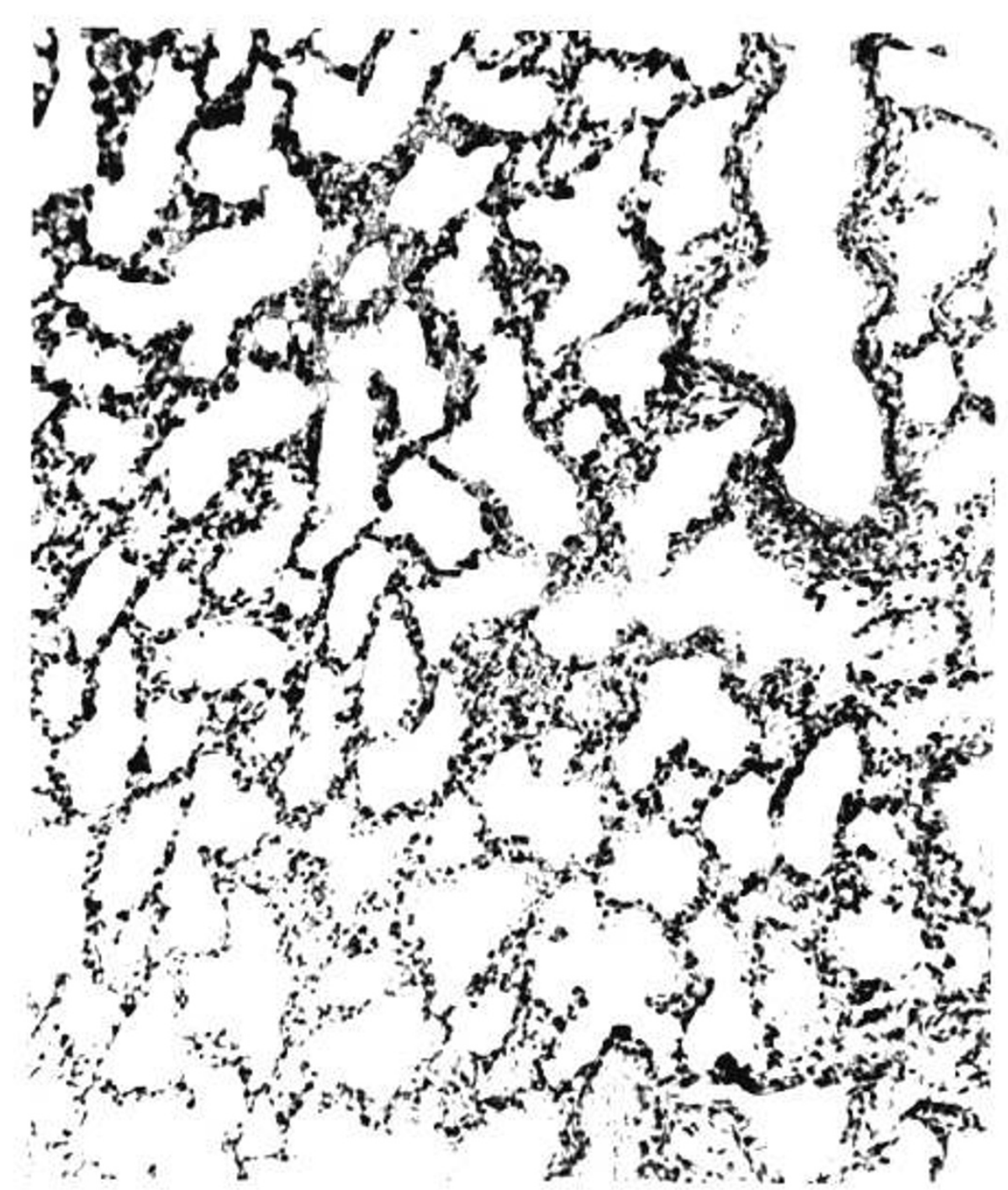




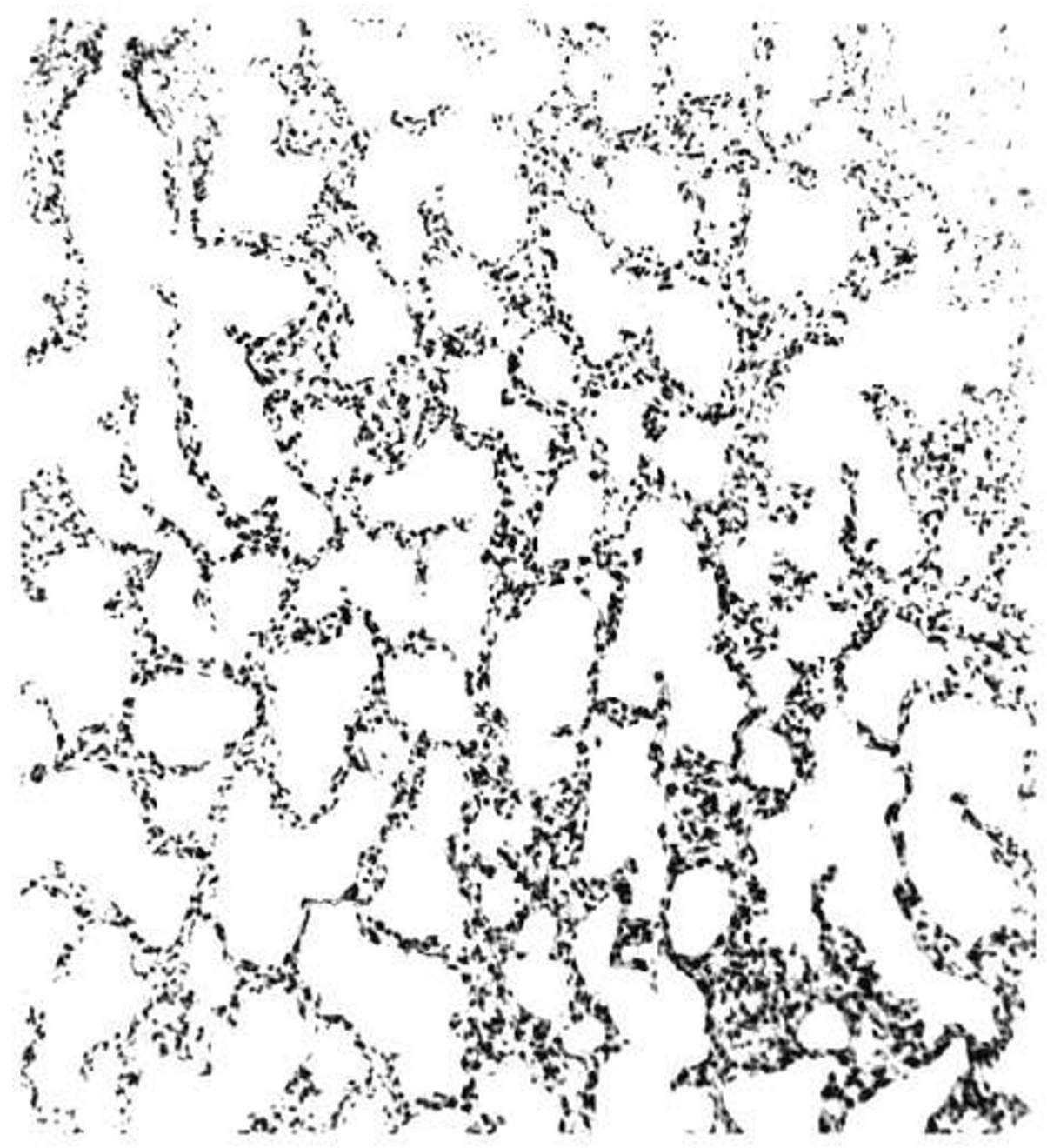

Fig. 3. A light micrograph of lung from a 72 -hr-old rabbit treated with vitamin $\mathrm{E}(6 \mathrm{mg} / 100 \mathrm{~g} /$ day $)$ and maintained in $100 \%$ oxygen since birth. This specimen is histologically indistinguishable from Figure 2 . Alveoli are of uniform size and shape, alveolar walls are delicate, and no atelectasis or emphysema are observed. (Hematoxylin and eosin, original magnification $\times 140$ ).

Table 8. The influence of vitamin $E$ on lung morphometric response to $72 \mathrm{hr}$ exposure to $100 \%$ oxygen

Morphometric analysis of lung injury

(\% each histologic specimen)

\begin{tabular}{lccc}
\cline { 2 - 4 } & Room air & $100 \%$ oxygen & $\begin{array}{c}100 \% \text { oxygen }+ \\
\text { vitamin } \mathrm{E}\end{array}$ \\
\hline$\%$ atelectasis & $10.4 \pm 1.9^{1}$ & $40.3 \pm 5.6^{2}$ & $9.3 \pm 5.5$ \\
$\%$ emphysema & $8.0 \pm 2.0$ & $16.4 \pm 3.2$ & $7.1 \pm 2.5$ \\
$\%$ normal & $81.6 \pm 3.5$ & $43.3 \pm 8.5^{2}$ & $83.6 \pm 7.7$ \\
Total & & & \\
\hline
\end{tabular}

'Mean \pm S.F. Experimental conditions and statistical analysis were as described in Table 1 .

"Statistically significant difference from both the room air and $100 \%$ oxygen + vitamin $\mathrm{E}$ groups $(P<0.01)$. The increased percentage emphysema in the $100 \%$ oxygen group approached statistical significance $(P=$ 0.09 ).

of free radicals present in excess to available vitamin $E$. When the vitamin $E$ dose was increased to $6 \mathrm{mg} / 100 \mathrm{~g} /$ day, a protective effect on lung morphology was observed. Taken together with the biochemical findings at a lower vitamin $\mathrm{E}$ dose, these morphologic findings of antioxidant protection with vitamin $E$ treatment provide further evidence of an antioxidant effect of vitamin $E$ in lung.

\section{REFERENCES AND NOTES}

I. Aprille, J. R., and Rulfs, J.: A convenient neonatal model for developmental studies requiring artificial diets. Biol. Neonate, 30: 109 (1976).

2. ( how, C. K., Plopper, C. G., and Dungworth. D. L.: Influence of dietary vitamin $E$ on the lungs of ozone-exposed rats. Environ. Res.. 20: 309 (1979).

3. Clark, J. M. and Lambertsen. (C. J.: Pulmonary oxygen toxicity: a review. Pharmacol. Rev. 23: 37 (1971).

4. Crapo, J. D., and Tierney. D. F.: Superoxide dismutase and pulmonary oxygen toxicity. Am. J. Physiol.. 226: 1401 (1974).

5. Demopoulos. H. B.: The basis of free radical pathology. Fed. Proc., 32: 1859 (1973).

6. Edwards, D. K., Dyer. W. M.. and Northway, W. H., Jr.: Twelve years experience with bronchopulmonary dysplasia. Pediatrics. 59: 839 (1977).

7. Ehrenkranz., R. A.. Bonta. B. W.. Ablow. R. C... and Warshaw, J. B.: Amelioration of bronchopulmonary dysplasia after vitamin $E$ administration. N. Engl. J. Med., 299: 564 (1978).

X. Fahianek. J.. DeFilippi. J.. Richards. T., and Herp. A.: Micromethod for tocopherol determinations in blood serum. Clin. ('hem.. 14:456 (1968).

9. Feeny. L.. and Berman. E. R.: Oxygen toxicity: membrane damage by free radicals. Invest. Ophthalmol.. 15: 789 (1976).

10. Frank, L., Bucher, J. R., and Roberts, R. J.: Oxygen toxicity in neonatal and adult animals of various species. J. App. Physiol., 45: 699 (1978).

11. Gershman. R.: The biological effects of increased oxygen tension. In: K. E. Schaefer: Man's Dependence on the Earthly Atmosphere. pp. 171-178 (The MacMillan Co., New York, 1962).

12. Gilbert. D. L.: The role of pro-oxidants and antioxidants in oxygen toxicity. Radiat. Res. Suppl., 3: 44 (1963).

13. Harris, P. L., and Embree. N. D.: Quantitative consideration of the effect of polyunsaturated fatty acid content of the diet on the requirement for vitamin E. Am. J. Clin. Nutr., 1.3: 385 (1963).

14. Hagaard, N.: Cellular mechanisms of oxygen toxicity. Physiol. Rev.. 48: 311 $(1968)$.

15. Horn, H. D.: Glutathionine reductase. In: H. U. Bergmeyer: Methods of Enzymatic Analysis. p. 875-879 (Academic Press, New York. 1965). 
16. Horwitt. M. K.. Harvey, C. C.. Century. B.. and Whitting. L. A.: Polyunsaturated lipids and tocopherol requirements. J. Am. Diet. Assoc. 38: 231 (1961).

17. Horwitt. M. K.. Harvey. C. C.. Duncan. (i. D.. and Wilson, W. C.: Effects of limited tocopherol intake in man with relationships to erythrocyte hemolysis and lipid oxidations. Am. J. Clin. Nutr., 4: 408 (1956).

18. Kann. H. E., Jr.. Mengel. C. E.. Smith. W.. and Horton, B.: Oxygen toxicity and vitamin E. Aerosp. Med.. 3.5: 840 (1964).

19. Kimball, R. E., Reddy. K.. Peirce. T. H., Schwartz. L. W. Mustafa, M. (i., and Cross, C. E.: Oxygen toxicity: augmentation of antioxidant defense mechanisms in rat lung. Am. J. Physiol., 230: 1425 (1976).

20. Lowry. O. H., Rosebrough, N. J.. Farr. A. L., and Randall, R. J.: Protein measurement with the Folin phenol reagent. J. Biol. Chem. 193: 265 (1951).

21. Lucy. J. A.: Functional and structural aspects of biological membranes: A suggested structural role for vitamin $E$ in the control of membrane permeability and stability. Ann. N. Y. Acad. Sci.. 203: 4 (1972).

22. Misra. H. P. and Fridovich. I.: The role of superoxide anion in the autoxidation of epinephrine and a simple assay for superoxide dismutase. J. Biol. Chem. 247: 3170)(1972)

23. Nishiki. K.. Jameson. D., Oshino, N., and Chance, B.: Oxygen toxicity in the perfused rat liver and lung under hyperbaric conditions. Biochem. J., I60): 34 (1976).

24. Norhway. W. H., Jr.. Rosan. R. C.. and Porter. D. Y.: Pulmonary disease following respirator therapy of hyaline-membrane disease. N. Engl. J. Med.. 276: 357 (1967).

25. Paglia. D. E., and Valentine. W. N.: Studies on the quantitative and qualitative characterization of erythrocyte glutathione peroxidase. J. Lab. Clin. Med., 70) $158(1967)$.

26. Philip. A. G. S.: Oxygen plus pressure plus time: the etiology of bronchopulmonary dysplasia. Pediatrics, 55: 44 (1975).

27. Poland. R. L.. Bollinger. R. O.. Boz.ynski. M. E., Karna, P., and Perrin. E. V. D.: Effect of vitamin $E$ deficiency in pulmonary oxygen toxicity. Pediatr. Res., 11: 577A (1977)

28. Saltzman. H. A.. and Fridovich. I.: Oxygen toxicity. Introduction to a protective enzyme: Superoxide dismutase. Circulation. 48: 921 (1973).

Copyright (1) 1981 International Pediatric Research Foundation. Inc. $0031-3998 / 81 / 1503-0262 \$ 02.00 / 0$
29. Sinnhuber. R. O.. and Yu, T. C.: 2-Thiobarbituric acid method tor the measurement of rancidity in fishery products. Food Technol.. 12: 9 (1958).

30. Tappel. A. L.: Vitamin E as the biological lipid antioxidant. Vitam. Horm., 20) 493 (1962).

31. Tappel. A. L.: Lipid peroxidation damage to cell components. Fed. Proc., 32. 1870 (1973).

32. Taylor, D. W.: The effects of vitamin E deficiency on oxygen toxicity in the rat. J. Physiol (Lond.), 121: 49p (1953).

33. Taylor. D. W.: The effects of vitamin $E$ and of methylene blue on the manifestations of oxygen poisoning on the rat. J. Physiol. (Lond.), 131: 200 (1956).

34. Taylor, S. L., Lamden, M. P., and Tappel, A. L.: Sensitive fluorometric method for tissue tocopherol analysis. Lipids, 11: 530 (1976).

35. Weibel, E. R.: Stereological techniques for electron microscopic morphometry In: M. A. Hayat: Principles and Techniques of Electron Microscopy. Vol. 3. pp. 237-296 (van Nostrand-Reinhold. New York. 1973).

36. Whitting, L. A.: Vitamin E-polyunsaturated lipid relationship in diet and tissues. Am. J. Clin. Nutr.. 27: 952 (1974).

37. Winer. B. J.: Statistical Principles in Experimental Design. (McGraw-Hill Book Co.. New York, 1962).

38. Workshop on bronchopulmonary dysplasia. J. Pediatr. 85: 859 (1979)

39. Yam. J.. Frank. L., and Roberts, R. J.: Oxygen toxicity: comparison of lung biochemical responses in neonatal and adult rats. Pediatr. Res., 12:115 (1978)

40. The authors are grateful to Robert Kimura. M.D.. and Mary Terry for thei suggestions and technical assistance, to David Scott. Ph.D., for his advice and dedicated assistance in statistical analyses. and to Debra Camputaro for typing this manuscript.

41. Requests for reprints should be addressed to: Dr. Joseph Warshaw. Departmen of Pediatrics. Yale University School of Medicine, 333 Cedar Street. New Haven. (T 06510 .

42. This research was supported by United States Public Health Service Gran HD10949. Dr. Wender was supported by United States Public Health Service Research Fellowship Award HD 07094.

43. Received for publication June 18. 1980.

44. Accepted for publication September 12, 1980. 